\title{
Initial Cytotoxicity of Mineral Trioxide Aggregate (MTA) during Setting on Human Mesenchymal Stem Cells
}

\author{
Soo-Youn Kim, ${ }^{1}$ Su-Min Lee, ${ }^{1}$ and Jung-Hwan Lee $\mathbb{D}^{1,2,3,4}$ \\ ${ }^{1}$ Department of Biomaterials Science, College of Dentistry, Dankook University, Cheonan 31116, Republic of Korea \\ ${ }^{2}$ Institute of Tissue Regeneration Engineering (ITREN), Dankook University, Cheonan 31116, Republic of Korea \\ ${ }^{3}$ Department of Nanobiomedical Science \& BK21 PLUS NBM Global Research Center for Regenerative Medicine, \\ Dankook University, Cheonan 31116, Republic of Korea \\ ${ }^{4}$ UCL Eastman-Korea Dental Medicine Innovation Centre, Dankook University, Cheonan 31116, Republic of Korea
}

Correspondence should be addressed to Jung-Hwan Lee; ducious@gmail.com

Received 21 August 2019; Accepted 18 September 2019; Published 16 October 2019

Guest Editor: Lavinia C. Ardelean

Copyright (c) 2019 Soo-Youn Kim et al. This is an open access article distributed under the Creative Commons Attribution License, which permits unrestricted use, distribution, and reproduction in any medium, provided the original work is properly cited.

Bone-marrow-derived human mesenchymal stem cells (hMSCs) which are important cell source for hard tissue regeneration stay near periapical lesions of tooth, playing an essential role in periodontal regeneration. Since the biomineralization process of MSCs is largely governed by the initial local environment, it is crucial to know the biological effects of dental bioceramic (mineral trioxide aggregate (MTA)) right after implantation. The purpose of this study was to evaluate the initial cytotoxicity of 4 different commercially available MTA materials (Endocem MTA, Ortho MTA, ProRoot MTA, and MTA Angelus) against hMSCs during or after setting using extracts of materials. The materials were mixed separately and placed into disk-shaped Teflon split molds (10 $\mathrm{mm}$ diameter and $2 \mathrm{~mm}$ thickness), and the sample discs were separated and eluted in the culture medium for $24 \mathrm{~h}$. The extracts were exposed to hMSCs, and cytotoxicity was evaluated by the WST assay. In the present study, all 4 MTA products tested showed severe cytotoxicity at $100 \%$ and $50 \%$ extract, while $25 \%$ and $12.5 \%$ revealed $30 \sim 100 \%$ depending on the MTA products. Endocem MTA showed severe cytotoxicity at $12.5 \%$ extract, while others showed relatively higher cell viability compared to Endocem MTA. Images of live and dead cells represented less live cells at $25 \%$ and $12.5 \%$, confirming cell viability assay. Therefore, careful consideration of the concentration of MTA extracts is necessary, especially when applying MTA to the elderly patients to maintain the viability of hMSCs.

\section{Introduction}

When periapical tissues, which are alveolar bone and periodontal ligament that surrounds the root of the tooth, regenerate after pulp (soft tissue inside of tooth) infection and periapical lesion due to tooth decay, mesenchymal stem cells (MSCs) or osteoblastic precursors recruit and differentiate into osteoblasts during healing process $[1,2]$. The biomineralization process of MSCs is largely governed by local environment such as stiffness, stress relaxation, nanotopology, and chemicals [3-8]. The setting time of the materials applied in periapical lesion of tooth and the consequent biological functions of MSCs during setting after implantation are important for the healing process of inflamed periapical lesions. Because the biological effects of the implanted materials are largely dependent on the contact time between materials and tissue, the ingredients and their amounts released from implant biomaterials give contact time dependent influence to MSCs' behaviors and biological functions [9-12].

Conventionally, a number of biomaterials such as zinc oxide eugenol, gutta-percha, composite resin, and glass ionomer have been used as root-end (periapical) filling materials [13]. However, all of them are still suboptimal as root-end filling materials due to their bioinert property or less bioactivity [14]. Therefore, mineral trioxide aggregate (MTA) has been developed and widely utilized in clinics for perforation repair, pulpotomy, direct/indirect pulp capping, 
and apexification due to its good sealing ability, osteogenesis/odontogenesis, biocompatibility, and antibacterial activity and bioactive property $[15,16]$.

Many studies have focused on the effects of MTA when used for pulp healing, and researchers have majorly studied biological effects (i.e., cytotoxicity) with human dental pulp stem cells, not MSCs [17-21]. In addition, the concentrations of the extracts used for cytotoxicity test against human dental pulp stem cells were not diverse, which could not mimic clinically available microenvironment [21-24]. However, when MTA is applied for apical tissue regeneration, during and after the setting, MSCs staying nearby play an important role as critical cell source to fill the bone degraded due to infection $[9,25]$. However, limited studies have been performed to investigate the cytotoxicity of MTA with MSCs (or other stem cells) especially during setting $[9,21,24]$.

Thus, the purpose of this study was to evaluate the initial cytotoxicity (24 hr) of 4 different commercially available MTA materials (Endocem MTA, Ortho MTA, ProRoot MTA, and MTA Angelus) against bone-marrow-derived human mesenchymal stem cells (hMSCs) during or after setting using the extracts of materials (Figure 1). The null hypothesis was that there are no differences of cytotoxicity among MTA products.

\section{Materials and Methods}

2.1. Sample Preparation and Extraction. Materials used in the study were Endocem MTA (Maruchi, Wonju-si, South Korea), Ortho MTA (BioMTA, Seoul, South Korea), ProRoot MTA (Dentsply, Tulsa Dental, Tulsa, OK, USA), and MTA Angelus (Londrina, Paraná, Brazil). 4 different materials were chosen from market (Table 1); ProRoot MTA as a golden standard MTA, MTA Angelus as a MTA from another continent (South America), and Endocem MTA and Ortho MTA as two recently developed MTA from Asia. They were mixed separately on the bottom of Falcon $100 \mathrm{~mm}$ cell culture dish (Corning, NY, USA) for 1 minute of mixing time and were placed into disk-shaped Teflon split molds (10 $\mathrm{mm}$ diameter and $2 \mathrm{~mm}$ thickness). After 2 minutes of packing time, the excess materials of the molds were removed by compressing with a glass slide (Corning). To examine the cytotoxicity of MTA during setting, the MTA sample discs separated from the Teflon molds were immersed completely in MesenPRO RS ${ }^{\mathrm{TM}}$ Medium (Gibco, Carlsbad, CA, USA) for extraction. Meanwhile, for the after setting group, MTAs in the same mold were incubated for $24 \mathrm{~h}$, which indicates complete setting, and then immersed in the medium. MesenPRO (Gibco) was composed of MesenPRO RS basal medium (Gibco), 1 bottle of MesenPRO RS growth supplement (Gibco), 1\% GlutaMAX (Gibco), and $1 \%$ penicillin/streptomycin (Invitrogen, Carlsbad, CA, USA). The volume of the extractant, $0.733 \mathrm{ml}$, was determined according to ISO standard 10993-5. Then, they were incubated at $37^{\circ} \mathrm{C}$ in $5 \% \mathrm{CO}_{2}$ and $95 \%$ air environment for $24 \mathrm{~h}$ in sealed $50 \mathrm{ml}$ tubes and then filtered using $0.20 \mu \mathrm{m}$ pore size filters (Corning $\mathrm{GmbH}$, Germany) and syringes. The medium for dilution was also incubated for $24 \mathrm{~h}$ and filtered.
2.2. Cell Culture. Low-passage (4-8) hMSCs were collected from a commercial company (RoosterBio, USA, MSC-003) for this study, proved to have stem cell surface markers and differentiation capacities as MSCs. Cell vials were removed from nitrogen and thawed in $37^{\circ} \mathrm{C}$ water bath. After MesenPRO $\mathrm{RS}^{\mathrm{TM}}$ Medium was added to the cells, they were centrifuged at 2,000 rpm for 3 minutes. Then, the previous medium was extracted. The hMSCs were transferred to a tissue culture flask containing MesenPRO RS ${ }^{\mathrm{TM}}$ Medium and incubated at $37^{\circ} \mathrm{C}$ in $5 \% \mathrm{CO}_{2}$ and $95 \%$ humidity. All culture systems used in the present study adhered to these conditions. The subcultures were made when they reached some density.

2.3. Cytotoxicity Assay. The cells were separated from the flask according to the previous protocol and viability, and the number of cells was determined using a LUNA-II automatic cell counter (Logos Biosystems, Anyang, South Korea). When cell viability was above $70 \%$, cells were seeded at initial density of $1 \times 10^{5}$ cells $/ \mathrm{ml}$ in each well of a 96-well plate (SPL Life Sciences, Pocheon, Gyeonggi-do, South Korea). 5-10 columns and 5 rows of 5 different extract concentrations $(100 \%, 50 \%, 25 \%, 12.5 \%$, and control) were used for each plate. More than two independent experiments were carried out. The seeded cells were incubated in $5 \% \mathrm{CO}_{2}$ and humidified air at $37^{\circ} \mathrm{C}$ for $24 \mathrm{~h}$. Then, the medium was extracted, and $100 \mu \mathrm{l}$ of the filtered extracts was transferred into each well of the $100 \%$ row of the 96 -well plates. The rest of the extracts were diluted using the filtered medium. $100 \mu \mathrm{l}$ of the filtered medium was transferred into each well of the control row. The plates were incubated at $37^{\circ} \mathrm{C}$ in humidified air and $5 \% \mathrm{CO}_{2}$. After $24 \mathrm{~h}$ of incubation, the solution was replaced with EZ-Cytox cell viability assay solution (Daeil Lab Service, Guro, Seoul, South Korea) according to the manufacturer's instructions for water-soluble tetrazolium salt (WST) assays. EZ-Cytox contains WSTs, which are reduced only in viable cells of mitochondria's electron transport systems. Consequently, WSTs are transferred to the orange-colored substance formazan. The same volume of $100 \mu \mathrm{l}$ of the mixture was put in each well containing cells, as well as in several blank wells. The plates were incubated in the same condition. $2 \mathrm{~h}$ later, the viability of the cells was measured using a multidetection microplate reader (Spectramax M2e, Molecular Devices, Sunnyvale, CA, USA) at a wavelength of $450 \mathrm{~nm}$. Higher absorbance indicated greater cell viability.

2.4. Cell Morphology Assessment. To assess the numerical cell viability, images of live and dead cells were observed by a semiconfocal laser scanning microscope (Celena, Logos Biosystems, Anyang, South Korea). After removing the media and washing with PBS, $0.5 \mu \mathrm{M}$ calcein AM and $2 \mu \mathrm{M}$ ethidium homodimer-1 solutions were added to the cells.

Cells and extracts were prepared in the same way as for the WST assay. The extraction concentration investigated was 25 and $12.5 \%$, and the filtered medium was used as the control group. After $24 \mathrm{~h}$ of growing, the extracts were replaced with $100 \mu \mathrm{l}$ of $2 \mu \mathrm{M}$ ethidium homodimer- 1 and 


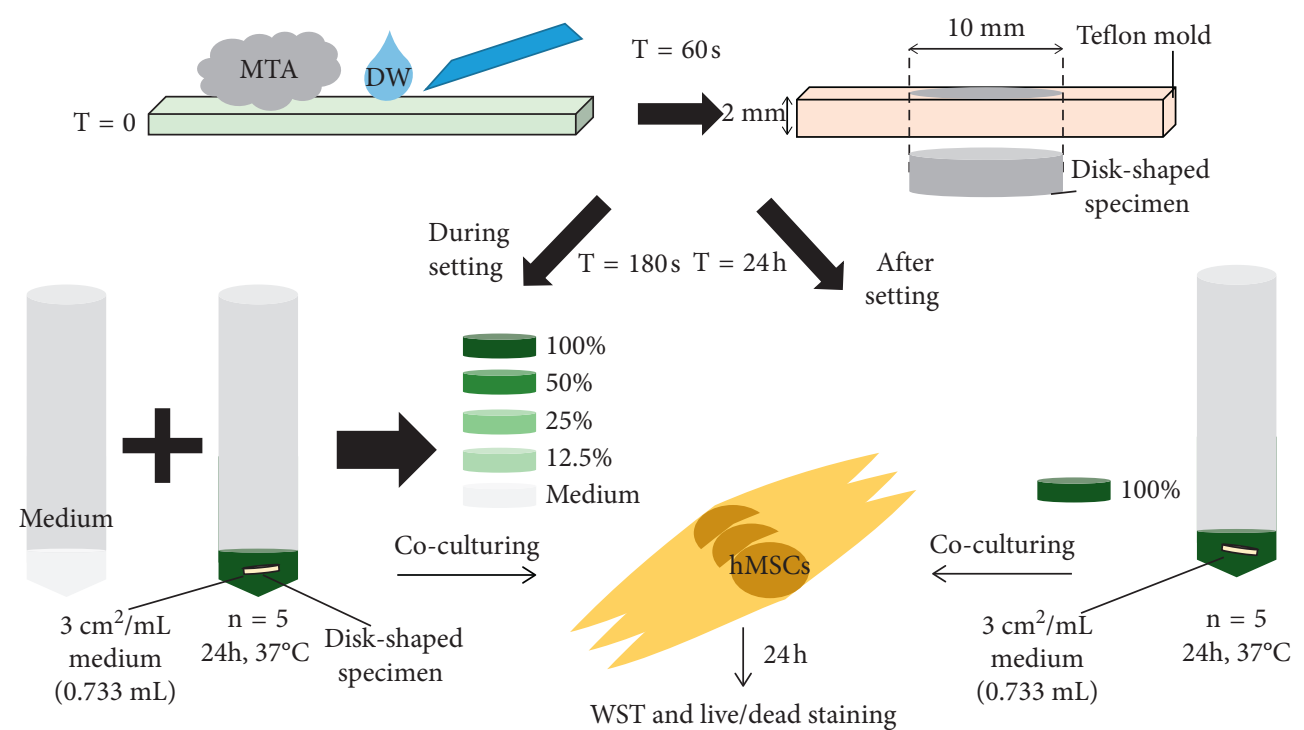

Figure 1: The methodology used in the present study. To examine cytotoxicity of MTA during setting or after setting, the MTA sample discs separated from the Teflon molds were immersed in media "during setting" (after $180 \mathrm{~s}$ ) or "after setting" (24 hr later).

TABLE 1: The properties of MTAs used in the present study.

\begin{tabular}{|c|c|c|c|c|c|}
\hline $\begin{array}{l}\text { Product } \\
\text { name }\end{array}$ & $\begin{array}{l}\text { Mixing ratio }(\mathrm{P} / \mathrm{L}) \\
(\mathrm{mg} / \mathrm{ml})\end{array}$ & $\begin{array}{l}\text { Initial setting } \\
\text { time }\end{array}$ & $\begin{array}{l}\text { Final setting } \\
\text { time }\end{array}$ & Manufacturer & Composition (\%) \\
\hline $\begin{array}{l}\text { Endocem } \\
\text { MTA }\end{array}$ & $300 / 0.12$ & $2 \min ( \pm 30 s)$ & $4 \min ( \pm 30 s)$ & $\begin{array}{l}\text { Maruchi (South } \\
\text { Korea) }\end{array}$ & $\begin{array}{c}\text { Natural pure cement (80) and bismuth } \\
\text { trioxide }(20)\end{array}$ \\
\hline Ortho MTA & $200 / 0.2$ & $180 \mathrm{~min}$ & $360 \mathrm{~min}$ & $\begin{array}{l}\text { BioMTA (South } \\
\text { Korea) }\end{array}$ & $\begin{array}{c}\text { Calcium carbonate }(60 \sim 80) \text {, silicon dioxide } \\
\text { (5 15), aluminium oxide }(5 \sim 10) \text {, and } \\
\text { dibismuth trioxide }(10 \sim 30)\end{array}$ \\
\hline $\begin{array}{l}\text { ProRoot } \\
\text { MTA }\end{array}$ & $500 / 0.167$ & $\begin{array}{l}78 \mathrm{~min} \\
( \pm 5 \mathrm{~min})\end{array}$ & $\begin{array}{c}261 \mathrm{~min} \\
( \pm 21 \mathrm{~min})\end{array}$ & Dentsply (USA) & $\begin{array}{c}\text { Portland cement }(60 \sim 90) \text { and bismuth } \\
\text { oxide }(10 \sim 40)\end{array}$ \\
\hline $\begin{array}{l}\text { MTA } \\
\text { Angelus }\end{array}$ & $140 / 0.467$ & $10 \mathrm{~min}$ & $15 \min$ & Londrina (Brazil) & $\begin{array}{l}\text { Tricalcium silicate }(45 \sim 60) \text {, dicalcium } \\
\text { silicate }(5 \sim 12) \text {, tricalcium aluminate } \\
(5 \sim 12) \text {, tetracalcium aluminoferrite }(1 \sim 7) \text {, } \\
\text { calcium oxide }(0 \sim 7) \text {, and bismuth oxide }\end{array}$ \\
\hline
\end{tabular}

$(15 \sim 30)$

The MTAs were mixed according to the manufacturer's instructions. Composition of MTA was given by each manufacturer.

$0.5 \mu \mathrm{M}$ calcein AM solutions and then dyed in the incubator according to the same condition for another 30 minutes. The cell morphology was seen with $4 \mathrm{x}$ magnification.

2.5. Statistical Analysis. The cytotoxicity data from different extraction starting points were statistically analysed by repeated measures analysis of variance (ANOVA). ANOVA was used for cytotoxicity comparison between serially diluted extract groups $(100,50,25,12.5$, and $0 \%)$ within the same product and extraction starting point. Tukey's post hoc test was used at levels of significance of $P<0.05$. The SPSS PASW version 23.0 software program (SPSS Inc.) was used.

\section{Results}

Figures 2 and 3 show the results of the WST cell viability assay. The viability of hMSCs when immersed in the eluates of four different MTAs was measured. Overall, all four MTA products tested showed severe cytotoxicity at $100 \%$ and $50 \%$ extracts, while $25 \%$ and $12.5 \%$ revealed $30 \sim 100 \%$ depending on the MTA products during setting. Endocem MTA still showed severe cytotoxicity at $12.5 \%$ extract, while others showed relatively higher cell viability compared to Endocem MTA. In detail, for Endocem MTA, the control group showed the highest cell viability followed by $12.5 \%$ and $25 \%$ (75.3\% and $27.9 \%$ cell viability, respectively). The cell viability of the $100 \%$ extract (5.3\% cell viability) was higher than the $50 \%$ dilution ( $3.4 \%$ cell viability). In Ortho MTA, the $12.5 \%$ concentration group $(102.3 \%$ cell viability) was the highest followed by the control group. The sequence of the viability of the rest was $25 \%>50 \%>100 \%$ (80.7, 5.4, and $1.2 \%$ cell viability, respectively), though the difference between the $50 \%$ and the $100 \%$ concentration groups was not significant. In ProRoot MTA, there was no significant difference between the control and the $12.5 \%$ concentration group ( $92.6 \%$ cell viability), and these two showed the highest cell viability. The $100 \%$ and the $50 \%$ concentration groups $(7.1 \%$ and $1.4 \%$ cell viability, respectively) were placed on the lowest. The $25 \%$ concentration group showed 


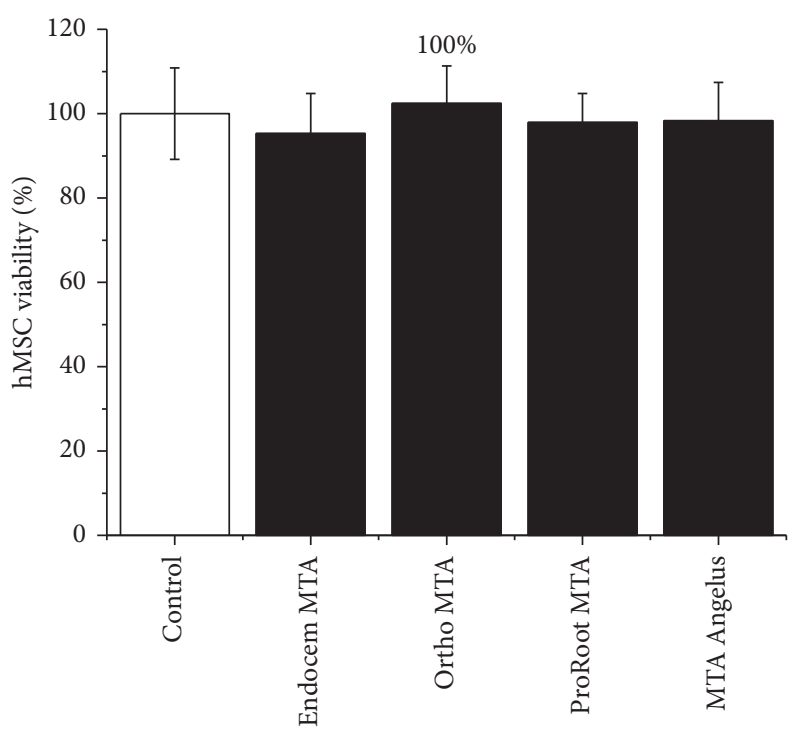

Figure 2: Results of cell viability of hMSCs at the $100 \%$ concentration of extracts from each MTA after setting. ${ }^{*} P<0.05$ and ${ }^{* *} P<0.01$ indicate statistically significant differences between cements and the control group. Each extract from four kinds of MTA after setting showed no cytotoxicity compared to control $(P>0.05)$.
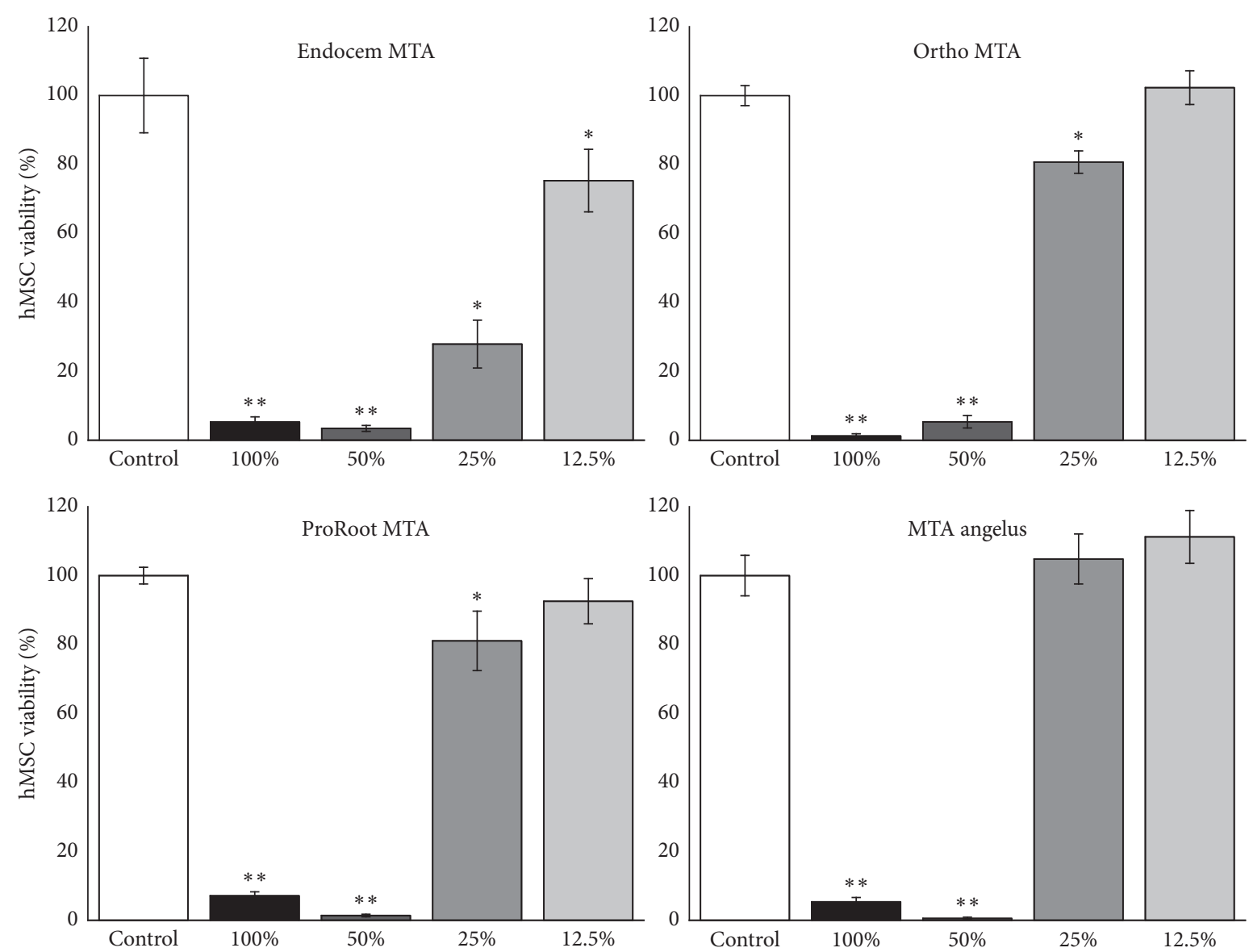

FiguRE 3: Results of cell viability of hMSCs at various concentrations of extracts from each MTA during setting. ${ }^{*} P<0.05$ and ${ }^{* *} P<0.01$ indicate statistically significant differences between cements and the control group. Cell viability from the extract during setting of all MTAs was significantly compromised with 100\%,50\%, and 25\% (except MTA Angelus) extracts, while cell viability from the $100 \%$ extract from set MTA was not compromised compared to control. 
cytotoxicity ( $81.1 \%$ cell viability). In the case of MTA Angelus, the $12.5 \%$ concentration group ( $111.2 \%$ cell viability) was the highest followed by the $25 \%$ concentration group ( $104.8 \%$ cell viability), and both showed higher viability than the control group. The pure extract and the 50\% concentration group showed $5.4 \%$ and $0.5 \%$ cell viability, respectively.

To confirm cell viability of $25 \%$ and $12.5 \%$ cultured conditions, a semiconfocal microscope was used. Live cells appear green and dead cells are indicated in red in the images (Figure 4).

Images of live and dead cells represented less live cells at $25 \%$ and $12.5 \%$, confirming cell viability assay. Meanwhile, the extracts of MTAs after setting showed similar cell viability with the control group. Since there were few live cells at $100 \%$ and $50 \%$ extracts, images were not shown.

\section{Discussion}

Bone and periodontal regeneration is a complicated process that requires the cooperation of myriad cells [25]. Mesenchymal stem cells (MSCs) or osteoblastic precursors recruit and differentiate into osteoblasts when periapical tissues of tooth surrounded by alveolar bone and periodontal ligament regenerate after pulpal infection and inflammation at periapical lesions due to tooth decay $[1,2]$. Still, the biomineralization process of MSCs is largely governed by local environment [3-8]. During tissue repair, especially in bone, blood vessels supply not only oxygen and nutrients but also calcium and phosphate which are needed for mineralization [26]. Thus, for healing inflamed periapical lesions, the setting time of the materials applied in periapical lesion and consequent biological functions of MSCs during setting are important since the biological effects of the implanted materials in periapical lesions are contact time-dependent and extracts during setting influence MSCs' behaviors [912]. Therefore, the effect of MTA against hMSCs was investigated in the present study.

Elution of MTAs starts right after its application, and the concentration of MTA eluents is expected to be high in the clinical situation. That is, when MTA is not completely set, chances are that toxic elements of MTA leach out and exert cytotoxicity. But before long, since the altering nature of the oral cavity makes the cytotoxicity weak and initial setting leads the materials to be structurally more stable, cytotoxicity decreases. In other words, due to this property of MTA elution, periradicular tissues are expected to be affected by a lower concentration of eluents over time [10]. This property of MTA might explain why MTA showed cytocompatibility in the previous studies but showed cytotoxicity in the present study $[9,10]$. Also, cell viability and proliferation are time-dependent. The longer the contact time, the better the cell viability. However, this study did not consider the effect of incubation time with extracts while previous studies assessed cell viability after $3 \sim 28$ days $[9,10,24]$.

To mimic clinical situation, the concentrations of the extracts used in the present study were diverse unlike previous studies [21-24]. The present study showed dosedependent effects of Endocem MTA, Ortho MTA, ProRoot
MTA, and MTA Angelus on hMSCs during setting. At $12.5 \%$, all materials evaluated except Endocem MTA showed cytocompatibility (90 110\%). MTA Angelus showed cytocompatibility even at 25\% (104\%). All four materials tested after setting showed cytocompatibility. These results agree with the previous ones showing noncytotoxicity $[9,10]$.

In contrast, all four materials tested during setting resulted in the most cytotoxicity at 100 and 50\% ( 5\%) which was quite different from previous studies $[9,24]$. This could be explained by the fact that the samples in those studies were set for $24 \mathrm{~h}$, which is enough time for the materials to set, and then immersed in the media. Meanwhile, in the present study, the specimens were immersed in culture media right after mixing for the condition of "during setting". Images of live and dead cells showed that Endocem MTA had much more cytotoxicity compared to ProRoot MTA along with previous compromised biological effects or high $\mathrm{pH}$ from set Endocem MTA compared to other set MTAs [27, 28]. Even though most of the reports revealed no significant cytotoxicity among various types of MTA, this cytotoxicity results from extract during setting of MTA showed significant difference among the groups [29]. Thus, according to the results, the null hypothesis that there are no differences of cytotoxicity among MTA products was rejected.

Since ProRoot MTA was first developed and became commercially available in the world, many researchers have studied the effects of MTA on ROS 17/2.8 [24], MG-63 cells, human gingival fibroblasts [30], and human dental pulp cells [31]. Few studies were conducted to investigate the effects of MTA on hMSCs, which utilized completely set MTA after $24 \mathrm{hr}$ after from the start of mixing [9]. Here eluates during or after setting of MTA were used with their advantages, which mimic microenviroment when they are implanted in periradicular lesion and affet cells continuously.

By observing cell viability of serially diluted extract groups $(100 \%, 50 \%, 25 \%, 12.5 \%$, and control), the result showed that cytotoxicity is dose-dependent. This also made it possible to determine the most proper concentration considering the sensitivity of hMSCs. $12.5 \%$ of Ortho MTA and ProRoot MTA and $12.5 \%$ and $25 \%$ of Angelus MTA show favorable results in this study.

Considering complex stages of wound healing and cytotoxicity of MTA in a particular situation, people whose quality of vascular supply to bone decreases might experience delayed bone healing compared to healthy and young people. This explains one of the reasons of incomplete healing with MTA associated with patients' condition. Further experiments regarding adverse effects to long-term cytotoxicity, differentiation ability, or stemness of MSCs from the extract of MTA will be necessary to investigate MTA's biological events depending on the tissue-MTA interacting condition (after setting or during setting) or types of MTA [8]. In addition, to reveal the mechanism which ingredient was involved to show different biological behaviors between "during setting" and "after setting" MTA, $\mathrm{pH}$ value and ion concentration or type (hydroxyl ion, $\mathrm{Ca}, \mathrm{Si}$, 


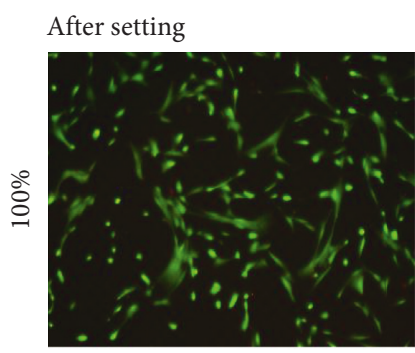

Endocem MTA Before setting
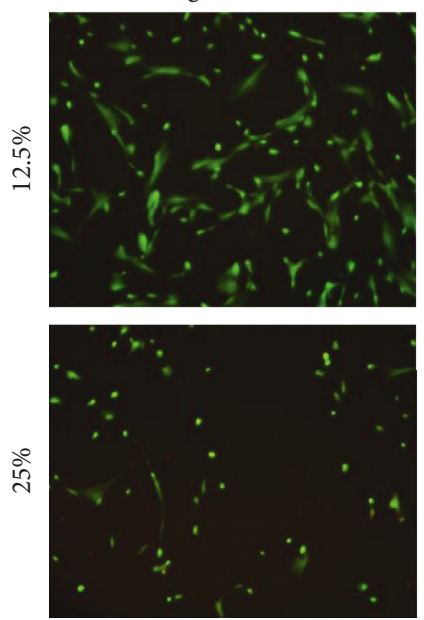

Endocem MTA

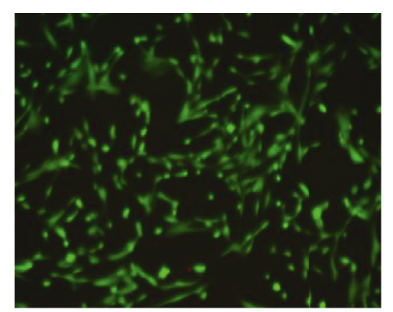

Ortho MTA
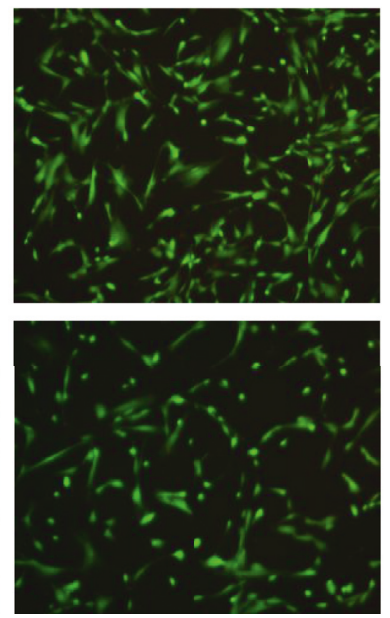

Ortho MTA

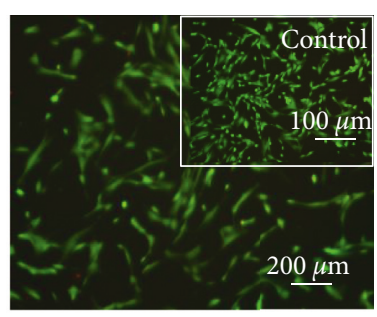

ProRoot MTA
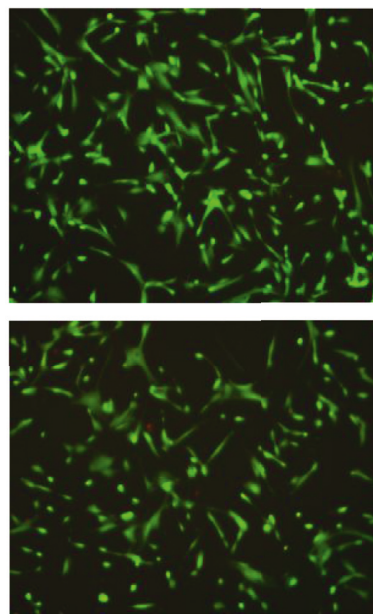

ProRoot MTA

Figure 4: Live and dead cells of hMSCs exposed to $12.5 \%$ and $25 \%$ concentrations of extracts from each MTA before and after setting. Live (green) and dead (red) cells were observed by the fluorescent microscope. Washing steps were performed before live and dead staining to make sure that only intact live cells remained on the plate. Because the dead cells (red colored) were easily detached during the washing step, they are hardly seen in the current images.

$\mathrm{Bi}, \mathrm{Al}$, other impurity element ions, etc.) will be investigated, which will be helpful for understanding MTA's biological effects during and after setting.

\section{Conclusion}

All four MTA products tested during setting showed severe cytotoxicity at original and 50\% extracts, while $25 \%$ and $12.5 \%$ revealed $30 \sim 100 \%$ cell viability depending on the MTA products. On the other hand, $100 \%$ extracts from completely set MTAs showed similar cell viability with the control group without cytotoxicity. To simulate a clinical situation, cytotoxicity and biological functions of MTAs to hMSCs during setting need to be considered. Extreme cytotoxicity of MTA might delay periodontal healing process, and this would happen more often with patients whose quality of vascular supply to bone decreases. Thus, careful consideration of cytotoxicity depending on the products is necessary before applying MTA to root apex.

\section{Data Availability}

The data used to support the findings of this study are included within the article.

\section{Conflicts of Interest}

The authors declare that they have no conflicts of interest.

\section{Authors' Contributions}

Soo-Youn Kim, Su-Min Lee, and Jung-Hwan Lee were responsible for conceptualization and investigation; Soo-Youn Kim was responsible for methodology; Soo-Youn Kim and Jung-Hwan Lee wrote the original draft; and Su-Min Lee and Jung-Hwan Lee reviewed and edited the manuscript.

\section{Acknowledgments}

This research was supported by the research fund of Dankook University in 2018.

\section{References}

[1] S. Kawai, H. Yoshitomi, J. Sunaga et al., "In vitro bone-like nodules generated from patient-derived iPSCs recapitulate pathological bone phenotypes," Nature Biomedical Engineering, vol. 3, no. 7, pp. 558-570, 2019.

[2] G. T.-J. Huang, W. Sonoyama, Y. Liu, H. Liu, S. Wang, and S. Shi, "The hidden treasure in apical papilla: the potential role in pulp/dentin regeneration and bioroot engineering," Journal of Endodontics, vol. 34, no. 6, pp. 645-651, 2008. 
[3] J.-H. Lee and H.-W. Kim, "Emerging properties of hydrogels in tissue engineering," Journal of Tissue Engineering, vol. 9, 2018.

[4] J.-H. Lee, D.-H. Kim, H.-H. Lee, and H.-W. Kim, "Role of nuclear mechanosensitivity in determining cellular responses to forces and biomaterials," Biomaterials, vol. 197, pp. 60-71, 2019.

[5] S. Khetan, M. Guvendiren, W. R. Legant, D. M. Cohen, C. S. Chen, and J. A. Burdick, "Degradation-mediated cellular traction directs stem cell fate in covalently crosslinked threedimensional hydrogels," Nature Materials, vol. 12, no. 5, pp. 458-465, 2013.

[6] A. J. Engler, S. Sen, H. L. Sweeney, and D. E. Discher, "Matrix elasticity directs stem cell lineage specification," Cell, vol. 126, no. 4, pp. 677-689, 2006.

[7] K. Boldbaatar, K. Dashnyam, J. C. Knowles, H.-H. Lee, J.-H. Lee, and H.-W. Kim, "Dual-ion delivery for synergistic angiogenesis and bactericidal capacity with silica-based microsphere," Acta Biomaterialia, vol. 83, pp. 322-333, 2019.

[8] S.-K. Jun, J.-H. Lee, and H.-H. Lee, "The biomineralization of a bioactive glass-incorporated light-curable pulp capping material using human dental pulp stem cells," BioMed Research International, vol. 2017, Article ID 2495282, 9 pages, 2017.

[9] V. D’Antò, M. P. Di Caprio, G. Ametrano, M. Simeone, S. Rengo, and G. Spagnuolo, "Effect of mineral trioxide aggregate on mesenchymal stem cells," Journal of Endodontics, vol. 36, no. 11, pp. 1839-1843, 2010.

[10] F. Costa, P. Sousa Gomes, and M. H. Fernandes, "Osteogenic and angiogenic response to calcium silicate-based endodontic sealers," Journal of Endodontics, vol. 42, no. 1, pp. 113-119, 2016.

[11] G. Fernandez de Grado, L. Keller, Y. Idoux-Gillet et al., "Bone substitutes: a review of their characteristics, clinical use, and perspectives for large bone defects management," Journal of Tissue Engineering, vol. 9, 2018.

[12] J. B. Norelli, D. P. Plaza, D. N. Stal, A. M. Varghese, H. Liang, and D. A. Grande, "Tenogenically differentiated adiposederived stem cells are effective in achilles tendon repair in vivo," Journal of Tissue Engineering, vol. 9, 2018.

[13] R. Holland, J. E. Gomes Filho, L. T. A. Cintra, Í. O. d. A. Queiroz, and C. Estrela, "Factors affecting the periapical healing process of endodontically treated teeth," Journal of Applied Oral Science, vol. 25, no. 5, pp. 465-476, 2017.

[14] M. Parirokh and M. Torabinejad, "Mineral trioxide aggregate: a comprehensive literature review-Part I: chemical, physical, and antibacterial properties," Journal of Endodontics, vol. 36, no. 1, pp. 16-27, 2010.

[15] M. Torabinejad and M. Parirokh, "Mineral trioxide aggregate: a comprehensive literature review-Part II: leakage and biocompatibility investigations," Journal of Endodontics, vol. 36, no. 2, pp. 190-202, 2010.

[16] H.-J. Moon, J.-H. Lee, J.-H. Kim et al., "Reformulated mineral trioxide aggregate components and the assessments for use as future dental regenerative cements," Journal of Tissue Engineering, vol. 9, 2018.

[17] A. Nowicka, M. Lipski, M. Parafiniuk et al., "Response of human dental pulp capped with biodentine and mineral trioxide aggregate," Journal of Endodontics, vol. 39, no. 6, pp. 743-747, 2013.

[18] E. M. Rodrigues, A. L. G. Cornélio, L. B. Mestieri et al., "Human dental pulp cells response to mineral trioxide aggregate (MTA) and MTA plus: cytotoxicity and gene expression analysis," International Endodontic Journal, vol. 50, no. 8, pp. 780-789, 2017.

[19] X. Zhao, W. He, Z. Song, Z. Tong, S. Li, and L. Ni, "Mineral trioxide aggregate promotes odontoblastic differentiation via mitogen-activated protein kinase pathway in human dental pulp stem cells," Molecular Biology Reports, vol. 39, no. 1, pp. 215-220, 2012.

[20] A. Leyendecker Junior, C. C. Gomes Pinheiro, T. Lazzaretti Fernandes, and D. Franco Bueno, "The use of human dental pulp stem cells for in vivo bone tissue engineering: a systematic review," Journal of Tissue Engineering, vol. 9, 2018.

[21] A. Paranjpe, H. Zhang, and J. D. Johnson, "Effects of mineral trioxide aggregate on human dental pulp cells after pulpcapping procedures," Journal of Endodontics, vol. 36, no. 6, pp. 1042-1047, 2010.

[22] B.-N. Lee, H.-J. Son, H.-J. Noh et al., "Cytotoxicity of newly developed ortho MTA root-end filling materials," Journal of Endodontics, vol. 38, no. 12, pp. 1627-1630, 2012.

[23] Z. Jaberiansari, S. Naderi, and F. S. Tabatabaei, "Cytotoxic effects of various mineral trioxide aggregate formulations, calcium-enriched mixture and a new cement on human pulp stem cells," Iranian Endodontic Journal, vol. 9, no. 4, pp. 271-276, 2014.

[24] H. Ogata, M. Hayashi, H. Tsuda et al., "Effects of a calcium phosphate cement on mineralized nodule formation compared with endodontic cements," Dental Materials Journal, vol. 31, no. 1, pp. 92-97, 2012.

[25] Y. Yang, F. M. V. Rossi, and E. E. Putnins, "Periodontal regeneration using engineered bone marrow mesenchymal stromal cells," Biomaterials, vol. 31, no. 33, pp. 8574-8582, 2010.

[26] S. Stegen, N. van Gastel, and G. Carmeliet, "Bringing new life to damaged bone: the importance of angiogenesis in bone repair and regeneration," Bone, vol. 70, pp. 19-27, 2015.

[27] M. Kim, W. Yang, H. Kim, and H. Ko, "Comparison of the biological properties of proroot MTA, orthoMTA, and endocem MTA cements," Journal of Endodontics, vol. 40, no. 10, pp. 1649-1653, 2014.

[28] K.-A. Kim, Y.-M. Yang, Y.-S. Kwon, Y.-C. Hwang, M.-K. Yu, and K.-S. Min, "Odontogenic effects of a fast-setting calciumsilicate cement containing zirconium oxide," Dental Materials Journal, vol. 34, no. 4, pp. 432-440, 2015.

[29] R. Emara, K. Elhennawy, and F. Schwendicke, "Effects of calcium silicate cements on dental pulp cells: a systematic review," Journal of Dentistry, vol. 77, pp. 18-36, 2018.

[30] R. J. Y. Kim and J. H. Shin, "Cytotoxicity of a novel mineral trioxide aggregated based root canal sealer," Dental Materials Journal, vol. 33, no. 3, pp. 313-318, 2014.

[31] S.-W. Chang, W.-J. Bae, J.-K. Yi et al., "Odontoblastic differentiation, inflammatory response, and angiogenic potential of 4 calcium silicate-based cements: micromega MTA, proroot MTA, retroMTA, and experimental calcium silicate cement," Journal of Endodontics, vol. 41, no. 9, pp. 1524-1529, 2015. 


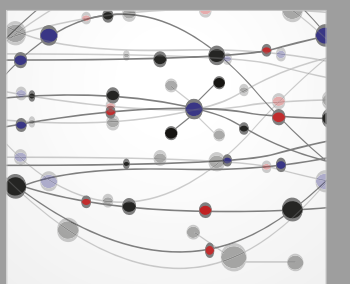

The Scientific World Journal
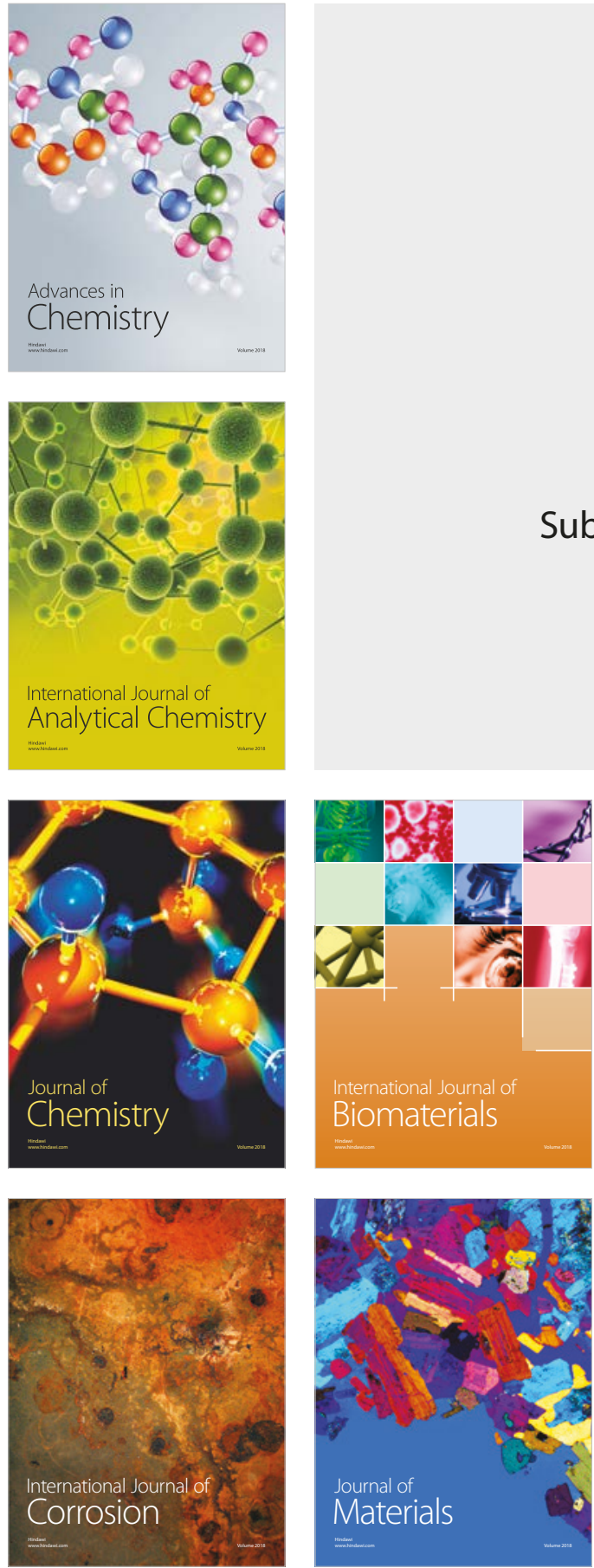

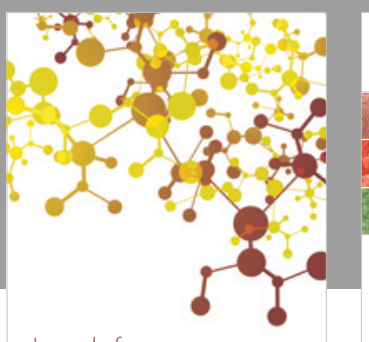

Journal of

Applied Chemistry
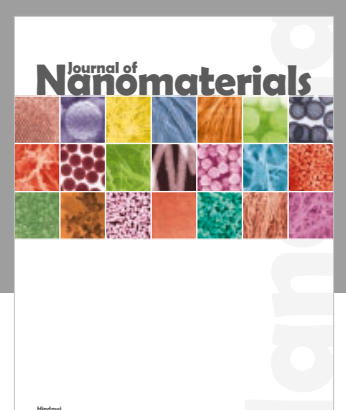

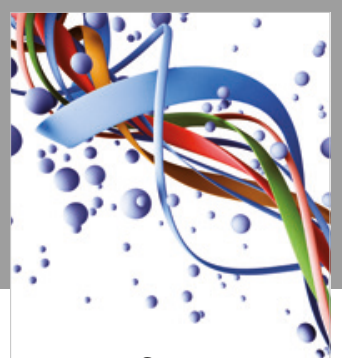

Scientifica

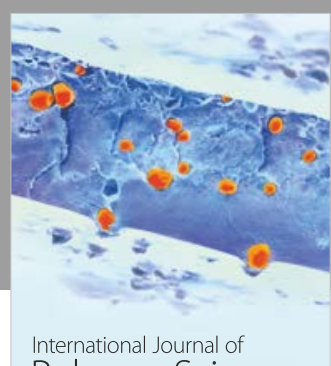

Polymer Science

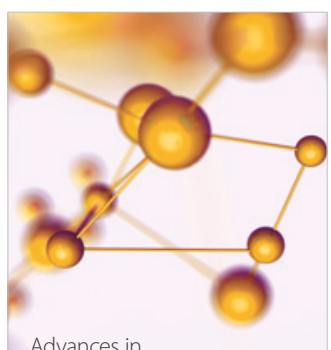

Physical Chemistry
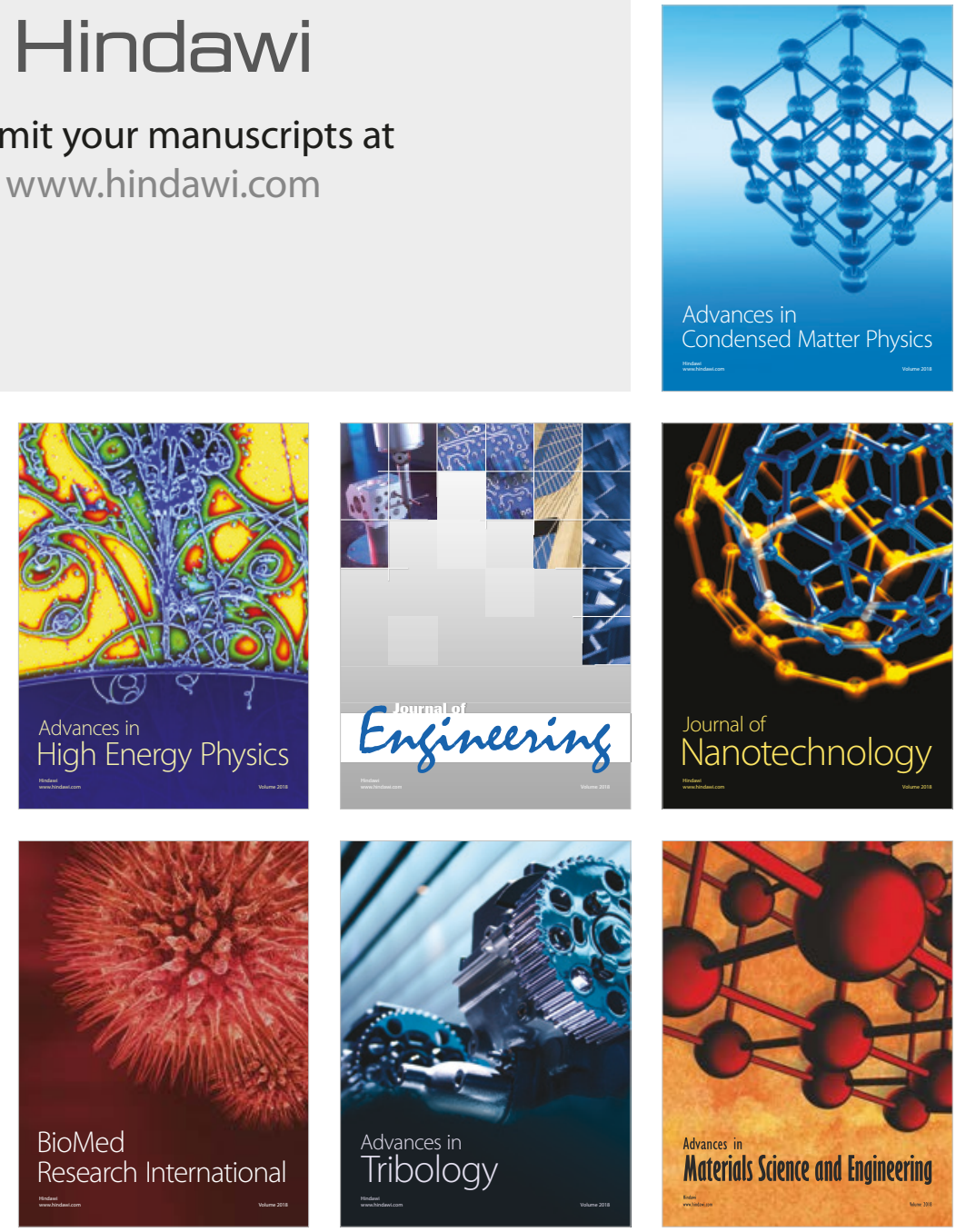